\title{
Expanding the phenotype of IQSEC2 mutations: truncating mutations in severe intellectual disability
}

\author{
Frederic Tran Mau-Them ${ }^{1}$, Marjolaine Willems ${ }^{\star}, 1$, Beate Albrecht ${ }^{2}$, Elodie Sanchez ${ }^{1}$, Jacques Puechberty ${ }^{1}$, \\ Sabine Endele ${ }^{3}$, Anouck Schneider ${ }^{4}$, Nathalie Ruiz Pallares ${ }^{4,5}$, Chantal Missirian ${ }^{6}$, Francois Rivier ${ }^{7}$, \\ Manon Girard $^{4}$, Muriel Holder ${ }^{8}$, Sylvie Manouvrier ${ }^{8}$, Isabelle Touitou ${ }^{5}$, Genevieve Lefort ${ }^{4}$, Pierre Sarda ${ }^{1}$, \\ Anne Moncla ${ }^{7}$, Severine Drunat ${ }^{9}$, Dagmar Wieczorek ${ }^{2}$ and David Genevieve ${ }^{1}$
}

Intellectual disability (ID) is frequent in the general population, with 1 in 50 individuals directly affected worldwide. The multiple etiologies include X-linked ID (XLID). Among syndromic XLID, few syndromes present severe ID associated with postnatal microcephaly and midline stereotypic hand movements. We report on three male patients with ID, midline stereotypic hand movements, hypotonia, hyperkinesia, strabismus, as well as seizures (2/3), and non-inherited and postnatal onset microcephaly (2/3). Using array CGH and exome sequencing we characterised two truncating mutations in IQSEC2, namely two de novo intragenic duplication mapped to the Xp11.22 region and a nonsense mutation in exon 7 . We propose that truncating mutations in IQSEC2 are responsible for syndromic severe ID in male patients and should be screened in patients without mutations in MECP2, FOXG1, CDKL5 and MEF2C.

European Journal of Human Genetics (2014) 22, 289-292; doi:10.1038/ejhg.2013.113; published online 15 May 2013

Keywords: syndromic X-linked intellectual disability; microcephaly; IQSEC2-truncating mutations

\section{INTRODUCTION}

Intellectual disability (ID) is defined by substantial limitations in cognitive functioning (intellectual quotient $<70$ ) coupled with a deficit in adaptive behaviour and onset before the age of 18 years. ID is frequent in the general population, with as many as 1 in every 50 individuals directly affected worldwide. ${ }^{1,2}$ Among the genetic etiologies of ID, XLID is a frequent cause, estimated at $5-10 \%$ of all cases in males, with a major genetic heterogeneity. Indeed, more than 102 genes have been involved in syndromic form of XLID, making molecular diagnosis and thus genetic counselling difficult. ${ }^{2-4}$ Among XLID, syndromic and nonsyndromic forms are delineated based on observed additional features that are associated with ID such as seizures, abnormal growth parameters, visceral or cerebral malformation, and so on. Recently, mutations in IQSEC2 (Sec7 domain of, and IQ-like domain) have been shown to cause nonsyndromic XLID with behavioural disturbance. ${ }^{5-8}$ We report on three male patients with severe syndromic XLID and truncating mutations in IQSEC2.

\section{PATIENTS AND METHODS}

\section{Patient 1}

This patient was referred to the Genetics Department for severe ID and postnatal microcephaly. He is the only child born to healthy unrelated parents native to the south of France. Pregnancy was uneventful. The boy was born at $371 / 2$ weeks of gestation full term by caesarean section due to an abnormal presentation. Birth measurements were in the normal range (occipital frontal circumference $(\mathrm{OFC}) 36 \mathrm{~cm},+1 \mathrm{SD}$; birth weight $3430 \mathrm{~g}$, mean; birth length $52.5 \mathrm{~cm},+1 \mathrm{SD})$. Postnatal course was marked by psychomotor retardation with neonatal hypotonia, hyperkinesia, strabismus and non-inherited progressive postnatal microcephaly with OFC at $-2 \mathrm{SD}$ at 6 months of age. He sat at 12 months and did not vocalize at 15 months. At the time of the last evaluation, he was 4 years old. He presented with normal facial features (Figure 1a). OFC was at $48 \mathrm{~cm},-2.5 \mathrm{SD}$; weight at $2 \mathrm{~kg},+2 \mathrm{SD}$ and length at $106 \mathrm{~cm},+1 \mathrm{SD}$. Language was not acquired and he could not walk alone. He had no purposeful hand skills, but had stereotypic hand movements such as hand washing/rubbing automatisms. He additionally had behavioural disturbances such as self injury and unexplained crying episodes. Epilepsy with generalised myoclonic seizures started at the age of 4 years. Eye examination revealed hypermetropia, leading to strabismus. Brain MRI with spectroscopy, heart and kidney ultrasounds, skeletal X-rays and ENT examination were normal. Metabolic screening including urinary organic acid chromatography and plasma lactate dosage, as well as congenital disorders of glycosylation screening test were also normal. Standard blood chromosomes and fluorescence in situ hybridisation (FISH) of the 22q11.2 region were normal. Methylation-sensitive PCR of the Prader-Willi/Angelman syndrome region and UBE3A sequencing analysis, as well as analysis of the MECP2, CDKL5, MEF2C and FOXG1 genes were normal.

\footnotetext{
${ }^{1}$ Departement de Genetique Medicale, Centre de Reference Maladies Rares Anomalies du Developpement et Syndromes Malformatifs Sud-Languedoc Roussillon, Hopital Arnaud de Villeneuve CHRU Montpellier, Faculte de Medecine Universite Montpellier 1, Montpellier, France; ${ }^{2}$ Institut fur Humangenetik, Universitatsklinikum Essen, Universitat Duisburg-Essen Hufelandstr, Essen, Germany; ${ }^{3}$ Humangenetisches Institut Erlangen, Universitat Erlangen-Nurnberg, Erlangen, Germany; ${ }^{4}$ Service de Genetique Chromosomique, Plateforme Puce a ADN, Hopital Arnaud de Villeneuve, CHRU Montpellier,Montpellier, France; ${ }^{5}$ Laboratoire de Genetique, Unite Medicale des Maladies AutoInflammatoire, Hopital Arnaud de Villeneuve, CHRU Montpellier, Faculte de Medecine, Universite Montpellier, Montpellier, France; ${ }^{6}$ Département de génétique médicale, Unité de génétique clinique, CHU de Marseille, Hôpital de la Timone, Marseille, France; ${ }^{7}$ Departement de Neuropediatrie, Hopital St Eloi, CHRU Montpellier, Montpellier, France; ${ }^{8}$ Departement de Genetique, Hopital Jeanne de Flandre, CHRU Lille, Lille, France; ${ }^{9}$ UF de Genetique Moleculaire et de Biochimie, Pole Biologie et Pharmacie, CHU Robert Debre, APHP

${ }^{*}$ Correspondence: Dr M Willems, Departement de Genetique Medicale, Centre de Reference Maladies Rares Anomalies du Developpement et Syndromes Malformatifs Sud-Languedoc Roussillon, Hopital Arnaud de Villeneuve CHRU Montpellier, Faculte de Medecine Universite Montpellier 1, 371 Avenue du Doyen Gaston Giraud, cedex 5, Montpellier 34295, France. Tel: +33 4673365 64; Fax: +33 4673360 52; Email: m-willems@chu-montpellier.fr
}

Received 4 December 2012; revised 5 March 2013; accepted 7 March 2013; published online 15 May 2013 

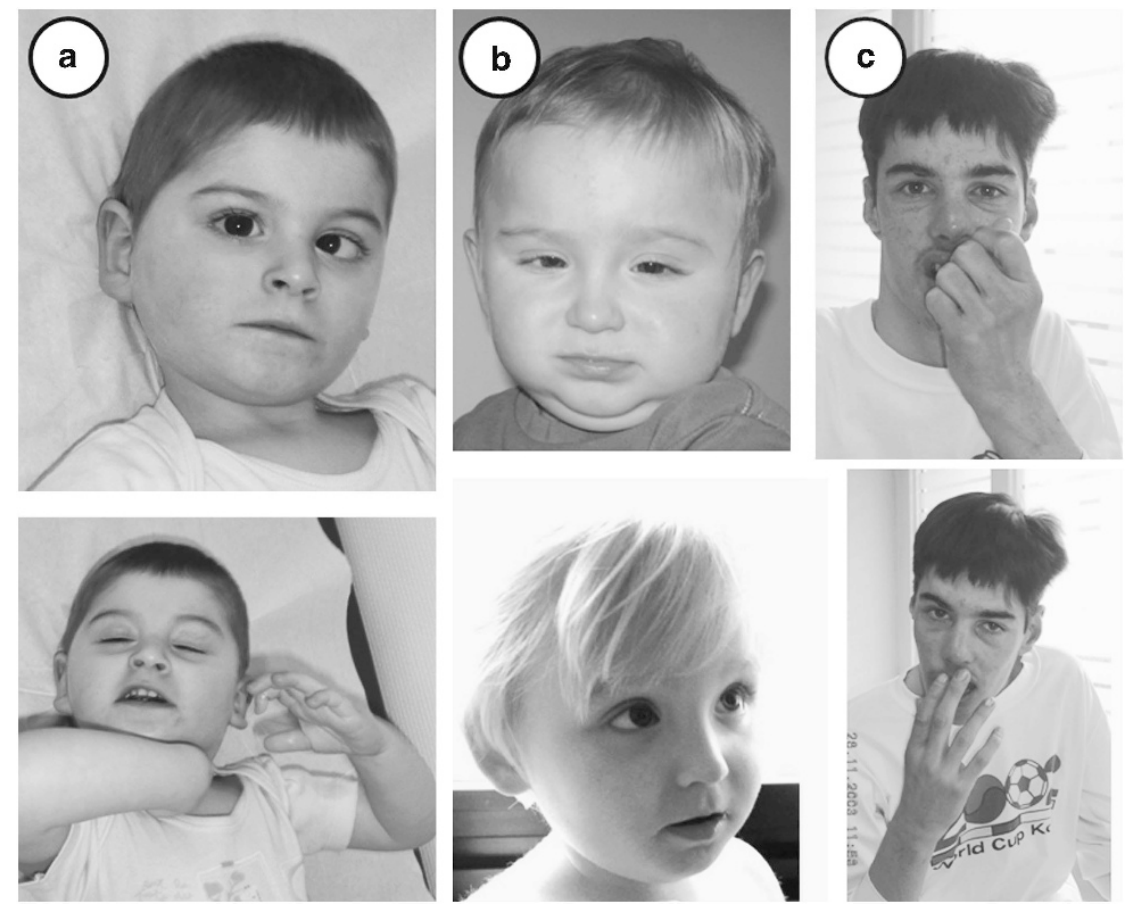

Figure 1 Front and lateral view of the patients. (a) Patient 1 . Note the strabismus and the median position of the hands suggestive of stereotypic midline movement of the hands. (b) Patient 2 at the age of 15 months and 31 months without specific facial dysmorphism. (c) Patient 3 at the age of 28 years. Note high forehead, short philtrum and full lipes. Note also median position of the hands, suggestive of stereotypic midline movement of the hands.

\section{Patient 2}

This patient is the only child of healthy, non-consanguineous German parents. Pregnancy was induced by hormone therapy and complicated by bleeding and cervical insufficiency. Caesarean section was performed at the 38th gestational week because of breech presentation. Birth measurements were normal (OFC $33 \mathrm{~cm},-1.36 \mathrm{SD}$; weight $2600 \mathrm{~g},-1.63 \mathrm{SD}$; length $52 \mathrm{~cm}, 0.7 \mathrm{SD}$ ). In infancy, muscular hypotonia, motor delay, brachycephaly, strabismus and autistic behaviour including avoiding eye contact, repetitive hand movements, focusing on one toy (ball) for a long time and restricting to few preferred actions were observed. Microcephaly was not observed in the first 2 years of life, but became obvious at the age of 2 and half years. He sat at 18 months, stood at 30 months and started to vocalize at the same time. Walking and talking were not achieved. Repetitive hand movements and temper tantrums were observed. At the age of the last investigation at 3 years he showed brachymicrocephaly, a high forehead, hypermetropia and strabismus (Figure 1b). Height and weight were normal but he presented with postnatal microcephaly (OFC $47 \mathrm{~cm},-2.46 \mathrm{SD}$; weight $16 \mathrm{~kg}$, mean; height $97 \mathrm{~cm}$, $-1.61 \mathrm{SD} ;$ ). EEG, brain MRI and metabolic screening were normal. Conventional and molecular karyotyping, fragile $\mathrm{X}$ testing and methylation-sensitive MLPA of the Prader-Willi/Angelman syndrome region gave normal results.

\section{Patient 3}

This patient is the first child born to healthy, unrelated parents. Pregnancy was uneventful. A baby boy was born at term by breech presentation. Birth weight was normal $(3600 \mathrm{~g}$, mean) but length and OFC were not recorded. Neonatal hypotonia was observed. At the age of 3 years, the boy developed partial epilepsy as well as midline stereotypic hand movements. He also presented strabismus. Language was partially acquired, but delayed and he walked alone at the age of 2 and half years. On the last evaluation, at 28 years of age, he presented with minor facial features (Figure 1c). Measurements were in the normal range (OFC $56 \mathrm{~cm},-0.5 \mathrm{SD}$; weight $48 \mathrm{~kg},+2 \mathrm{SD}$; length $175 \mathrm{~cm}$, $+1 \mathrm{SD}$ ). Between the age of 3 years and the last examination, both language and motor skills had regressed. In addition, he had developed behavioural disturbances including self injury. Brain MRI showed cerebral atrophy, with nonspecific hypersignal foci in periventricular white matter. Conventional blood karyotyping as well as analysis of the MECP2, CDKL5, MEF2C and FOXG1 genes were normal.

\section{Methods}

For patient 1 and 3, DNA was extracted from the patient's whole blood sample using the QIAamp DNA Blood Maxi Kit (QIAGEN, Courtaboeuf, France), according to the supplier's protocol. Microarray analysis was performed using SurePrint G3 Human CGH Microarray 180 K (Agilent, Santa Clara, CA, USA), according to the manufacturer's instructions. Results were processed and visualised by Cytogenomics 2.0 (Agilent) for patient 1, and by DNA analytics v 4.0.85 for patient 3. DNA sequence information referred to the public UCSC database GRCh37 (hg19). Potentially pathogenic copy number variations (CNV, defined as the copy number changes of 3 consecutive probes) were verified by $\mathrm{qPCR}$ and FISH in patient 1 and by CGH-array SurePrint G3 Human CGH Microarray 1 million (Agilent) for patient 3. FISH analysis was performed on metaphase chromosomes using two probes, according to the standard cytogenetic protocols. The probes included bacterial artificial chromosome clone RP13-497017 (Xp11.22, encompassing IQSEC2) for the duplicated region and a plasmid centromeric probe pLAX (DXZ1) as a control (kind gift from M Rocchi, University of Bari, Italy). Patient 2 was identified in an exome-sequencing study of 51 patients (19 males) with nonspecific severe ID, and has been briefly reported by Rauch et al. ${ }^{9}$ as patient E10-0275. Details on exome sequencing and Sanger sequencing are described therein. ${ }^{9}$

\section{RESULTS}

Microarray analysis in patient 1 retained only one potentially pathogenic $\mathrm{CNV}$, a 42-kb duplication mapped to the Xp11.22 region inside IQSEC2 (position X: 53283513-53325284, hg19). Microarray analysis in patient 3 retained a 22-kb duplication mapped to the Xp11.22 region inside IQSEC2 (position X: 


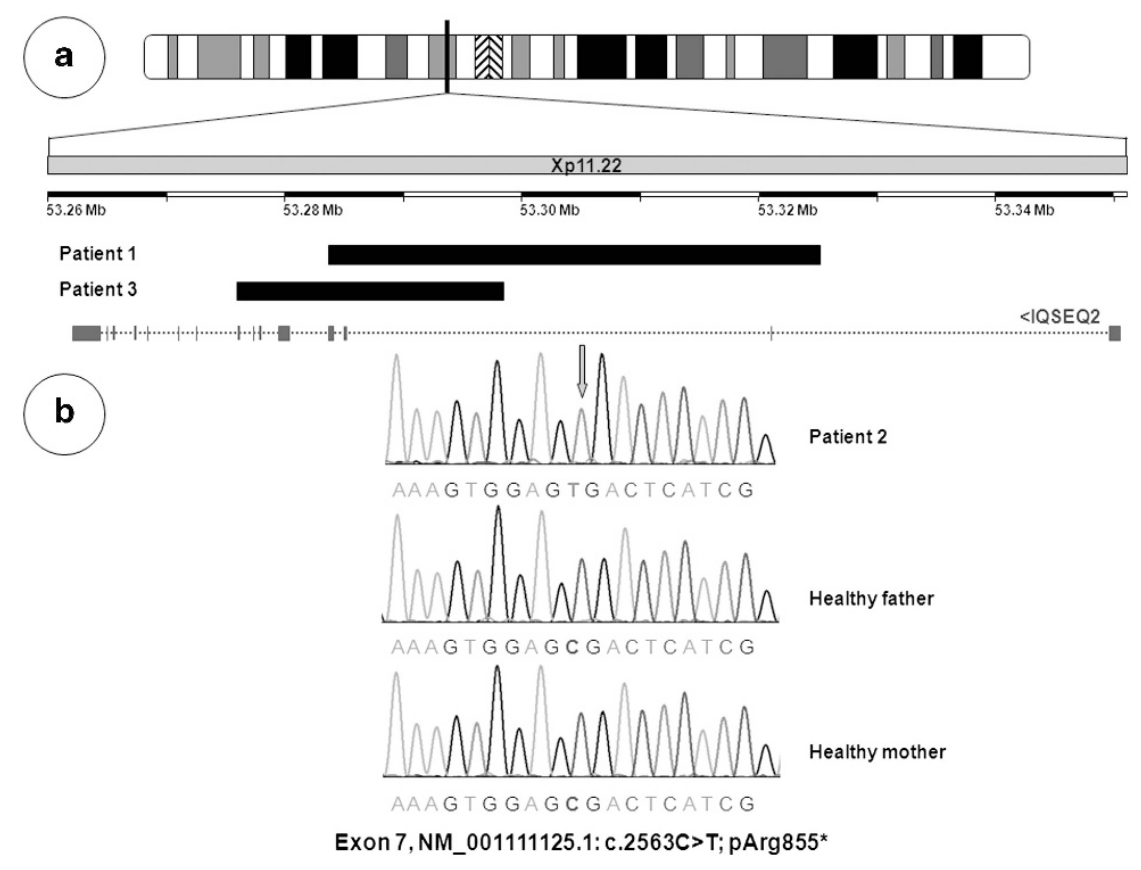

Figure 2 (a) Array CGH in patients 1 and 3, showing a small duplication of the IQSEC2 gene. (b) Partial sequence electrophoregrams of IQSEC2 exon 7 obtained from gDNA from patient 2, with a de novo hemizygous nonsense mutation in exon 7 (NM_001111125.1: c.2563C > T; pArg855*) and his healthy parents.

53276030-53298472, hg19). Based on the probes from the SurePrint G3 Human CGH Microarray $180 \mathrm{~K}$, duplication of IQSEC2 was intragenic and was between exon 2 and the end of exon 4 for patient 1 , and between intron 2 and the end of exon 8 for patient 3. The duplication was confirmed by qPCR using exon 2-specific probes of IQSEC2. Analysis of parental blood by $\mathrm{qPCR}$ determined a de novo occurrence of the duplication. FISH analysis using the RP13-497017 probe did not show an additional signal on any chromosome other than the $\mathrm{X}$ chromosome. IQSEC2 was thought to be disrupted by the intragenic duplication. A de novo hemizigous nonsense mutation in exon 7 (NM001111125.1: c.2563C > T; pArg855*) was identified in patient 2 (Figure 2). ${ }^{9}$ Exome and $\mathrm{CGH}$ microarray results are summarised in Figure 2.

\section{DISCUSSION}

We report on three male patients with a truncating mutation in IQSEC2 and severe syndromic ID characterised by progressive postnatal microcephaly, absence of speech and midline stereotypic hand movements similar to those observed in Rett or variant Rett syndromes. To date, mutations in IQSEC2 have been linked to nonsyndromic XLID in four unrelated families, with 32 male patients presenting moderate to severe ID and autistic features as reported by Shoubridge et al. ${ }^{7}$ In addition, 5/32 males also had seizures and 2/32 psychiatric disorders. Growth parameters including OFC were normal. Four different non-synonymous mutations in IQSEC2 were identified in these male patients. These mutations were predicted to lead to non-conserved amino acid substitutions within the key functional domains of IQSEC2. Our patients differ from the patients described by Shoubridge et $a l^{7}$ as they present a severe syndromic XLID phenotype namely severe ID and progressive microcephaly with postnatal onset (2/3), midline hand stereotypies (3/3) and seizures $(2 / 3)$. It is worthy to note that some female carriers had mild learning disabilities, which could be due to IQSEC2 partial loss of function. It is tempting to speculate that female carriers with severe truncating mutation may have a more severe phenotype than female carriers with non-synonymous mutations.

Interestingly, Morleo et al. ${ }^{6}$ described a girl born to healthy unrelated parents, sharing similarities with Rett syndrome, including speech regression, hypotonia, infantile spasms and severe ID since the age of 5 months. The patient presented with an apparently balanced $\mathrm{t}(\mathrm{X} ; 20)$, disrupting IQSEC2. This patient also had a complete skewed X-inactivation pattern with preferential use of the translocated chromosome. The clinical manifestations observed in this patient are thought to be due to disruption of IQSEC2. Table 1 summarises the clinical manifestations of the described patients from the literature and the patients described in this report.

IQSEC2 encodes for a guanine nucleotide exchange factor (GEF) that catalysed the exchange of GDP on GTP on Arf6, a small GTPase member of the ADP-ribosylation factor family. Shoubridge et al. ${ }^{8}$ demonstrated that mutation in IQSEC2 leads to significantly diminished GTP binding to ARF6 as compared with the wild types. They concluded that a loss of GEF activity of IQSEC2 is likely to be the underlying molecular mechanism of ID in patients with IQSEC2 mutations, probably by leading to reduced activation of the ARF6 substrate and influencing the regulation of actin cytoskeleton organisation. ${ }^{7,8,10}$

Interestingly, the patient reported by Morleo et al. ${ }^{6}$ and the three patients reported here presented with features observed in patients with MECP2, FOXG1, CDKL5 and MEF2C mutations (Table 1).

These genes, responsible for Rett syndrome and variant Rett syndrome, have been demonstrated to be involved in intracellular signalling pathways via small GTPases that have been divided into at least five families, namely Ras, Rho, Rab, Arf and Ran small GTPase. Small GTPases have a crucial role in cytoskeleton dynamics, 
Table 1 Clinical and biological features observed in patients with IQSEC2 mutations

\begin{tabular}{|c|c|c|c|c|c|c|c|c|}
\hline \multirow{2}{*}{$\begin{array}{l}\text { Reported } \\
\text { patients }\end{array}$} & \multicolumn{3}{|c|}{ Present report } & \multirow[t]{2}{*}{ Morleo et al ${ }^{6}$} & \multicolumn{4}{|c|}{ Shoubridge et al } \\
\hline & Patient 1 & Patient 2 & Patient 3 & & Family $1^{18,19}$ & Family $2^{20}$ & Family 3 & Family 4 \\
\hline $\begin{array}{l}\text { Number of } \\
\text { patients }\end{array}$ & 1 & 1 & 1 & 1 & 12 & 9 & 8 & 4 \\
\hline Birth OFC (cm) & 36 (+ 1 SD) & $33(-1,36 \mathrm{SD})$ & NR & Normal (NR) & NR & NR & NR & NR \\
\hline $\begin{array}{l}\text { Age at last } \\
\text { examination }\end{array}$ & 4 years & 3 years & 28 years & NR & NR & $14-30$ years & NR & NR \\
\hline OFC $(\mathrm{cm})$ & $48(-2,5 \mathrm{SD})$ & $47(-2,46$ SD) & $56(-0,5 \mathrm{SD})$ & NR & Normal & -2 to $+2 S D$ & NR & NR \\
\hline Gender & $1 \mathrm{M}$ & $1 \mathrm{M}$ & $1 \mathrm{M}$ & $1 \mathrm{~F}$ & $12 \mathrm{M}$ & $8 \mathrm{M} ; 1 \mathrm{~F}$ & $8 \mathrm{M}$ & $4 \mathrm{M}$ \\
\hline Strabismus & + & + & + & NR & NR & $1 / 8 \mathrm{M}$ & NR & NR \\
\hline $\begin{array}{l}\text { Motor } \\
\text { development }\end{array}$ & Delay & Delay & Regression & Delay & NR & Delay (1/6 M) & Delay (1/8) & ND \\
\hline $\begin{array}{l}\text { Intellectual } \\
\text { disability }\end{array}$ & Severe & Severe & Severe & Severe & Moderate & $\begin{array}{c}\text { Moderate to severe } 8 / 8 \mathrm{M} \text {; } \\
\text { moderate } 1 / 1 \mathrm{~F}\end{array}$ & Mild & $\begin{array}{l}\text { Mild to } \\
\text { moderate }\end{array}$ \\
\hline $\begin{array}{l}\text { Language } \\
\text { development }\end{array}$ & Not aquired & Not aquired & Regression & Delay & NR & Delay (4/8 M) & Delay (1/8) & Delay (3/4) \\
\hline $\begin{array}{l}\text { Midline } \\
\text { stereotypies }\end{array}$ & + & + & + & NR & NR & NR & NR & NR \\
\hline Seizures & + & - & + & + & $1 / 12$ & $2 / 8 \mathrm{M} ; 1 / 6 \mathrm{~F}$ & $0 / 8$ & $2 / 4$ \\
\hline Regression & - & - & + & + & NR & NR & NR & NR \\
\hline $\begin{array}{l}\text { Autism-like } \\
\text { behaviour }\end{array}$ & + & + & + & - & $0 / 12$ & $4 / 8 \mathrm{M} ; 1 / 6 \mathrm{~F}$ & $0 / 8$ & $1 / 4$ \\
\hline Mutation & $\begin{array}{l}\text { Truncating } \\
\text { duplication }\end{array}$ & $\begin{array}{l}\text { c. } 2563 \mathrm{C}>\mathrm{T}, \\
\mathrm{R} 855^{*}\end{array}$ & $\begin{array}{l}\text { Truncating } \\
\text { duplication }\end{array}$ & $\begin{array}{c}46, X X, t(X ; 20) \\
\text { (p11.2;q11.2) }\end{array}$ & $\begin{array}{c}\text { c. } 2587 \mathrm{C}>\mathrm{T}, \\
\mathrm{R} 863 \mathrm{~W}\end{array}$ & $\begin{array}{c}\text { c. } 2402 \mathrm{~A}>\mathrm{C}, \\
\text { Q801P }\end{array}$ & $\begin{array}{c}\text { c. } 2273 \mathrm{G}>\mathrm{A} \text {, } \\
\mathrm{R} 758 \mathrm{Q}\end{array}$ & $\begin{array}{c}\text { c. } 1075 \mathrm{C}>\mathrm{T} \text {, } \\
\mathrm{R} 359 \mathrm{C}\end{array}$ \\
\hline
\end{tabular}

Abbreviations: F, female; M, male; NR, not reported; OFC, occipital frontal circumference.

suggesting a common physiological pathway via abnormal small GTPase signalling ${ }^{11-17}$ in patients with severe ID, seizures, postnatal microcephaly and stereotypic midlines movements.

We propose that non-synonymous mutations in IQSEC2 leading to small functional perturbations are responsible for nonsyndromic XLID, whereas truncating mutations in IQSEC2 may generate a more severe loss of function of IQSEC2 that could explain the severe syndromic ID observed in the three reported patients, as well as the patient reported by Morleo et al. ${ }^{6}$

Based on these data, it appears legitimate to propose IQSEC2 molecular screening in patients with syndromic ID and Rett-like movements, and negative for mutations in MECP2, FOXG1, CDKL5 and $M E F 2 C$.

\section{CONFLICT OF INTEREST}

The authors declare no conflict of interest.

\section{ACKNOWLEDGEMENTS}

We thank the patients and their families. Part of this work was supported by the German Ministry of Education and Research. Part of this work was supported by a French research programme (Programme Hospitalier de Recherche Clinique Regional n ${ }^{\circ} 7890$ ) and by the French Health Ministry (Direction Generale de l'Organisation des Soins-DGOS). Note: patient consent was obtained for conducting the study.

1 Mulley JC, Kerr B, Stevenson R, Lubs H: Nomenclature guidelines for X-linked mental retardation. Am J Med Genet 1992; 43: 383-391.

2 Lubs HA, Stevenson RE, Schwartz CE: Fragile X and X-linked intellectual disability: four decades of discovery. Am J Hum Genet 2012; 90: 579-590.

3 Ropers $\mathrm{HH}: \mathrm{X}$-linked mental retardation: many genes for a complex disorder. Curr Opin Genet Dev 2006; 16: 260-269.
4 Stevenson RE, Schwartz CE: X-linked intellectual disability: unique vulnerability of the male genome. Dev Disabil Res Rev 2009; 15: 361-368.

5 Takai Y, Sasaki T, Matozaki T: Small GTP-binding proteins. Physiol Rev 2001; 81: 153-208.

6 Morleo M, laconis D, Chitayat D et al: Disruption of the IQSEC2 transcript in a female with $\mathrm{X}$; autosome translocation $\mathrm{t}(\mathrm{X} ; 20)(\mathrm{p} 11.2 ; \mathrm{q} 11.2)$ and a phenotype resembling X-linked infantile spasms (ISSX) syndrome. Mol Med Report 2008; 1: 33-39.

7 Shoubridge C, Tarpey PS, Abidi F et al: Mutations in the guanine nucleotide exchange factor gene IQSEC2 cause nonsyndromic intellectual disability. Nat Genet 2010; 42 486-488.

8 Shoubridge C, Walikonis RS, Gecz J, Harvey RJ: Subtle functional defects in the Arf specific guanine nucleotide exchange factor IQSEC2 cause non-syndromic X-linked intellectual disability. Small GTPases 2010; 1: 98-103.

9 Rauch A, Wieczorek D, Graf E et al: Range of genetic mutations associated with severe non-syndromic sporadic intellectual disability: an exome sequencing study. Lancet 2012; 380: 1674-1682.

10 Sakagami $H$, Sanda M, Fukaya $M$ et al: IQ-ArfGEF/BRAG1 is a guanine nucleotide exchange factor for Arf6 that interacts with PSD-95 at postsynaptic density of excitatory synapses. Neurosci Res 2008; 60: 199-212.

11 Abuhatzira L, Shamir A, Schones DE, Schaffer AA, Bustin M: MeCP2 involvement in the regulation of neuronal alpha-tubulin production. Hum Mol Genet 2009; 18: 1415-1423.

12 Matarazzo V, Cohen D, Palmer AM et al: The transcriptional repressor Mecp2 regulates terminal neuronal differentiation. Mol Cell Neurosci 2004; 27: 44-58.

13 Nectoux J, Florian C, Delepine C et al: Altered microtubule dynamics in Mecp2-deficient astrocytes. J Neurosci Res 2012; 90: 990-998.

14 De Filippis B, Fabbri A, Simone D et al: Modulation of RhoGTPases improves the behavioral phenotype and reverses astrocytic deficits in a mouse model of Rett syndrome. Neuropsychopharmacology 2012; 37: 1152-1163.

15 Ramakers GJ: Rho proteins, mental retardation and the cellular basis of cognition. Trends Neurosci 2002; 25: 191-199.

16 Nam JS, Yang H, Kim NH, Sun Y, Choi BS, Huh SO: A winged-helix transcription factor foxg1 induces expression of mss4 gene in rat hippocampal progenitor cells. Exp Neurobiol 2010; 19: 75-82.

17 Chen Q, Zhu YC, Yu J et al: CDKL5, a protein associated with rett syndrome, regulates neuronal morphogenesis via Rac1 signaling. J Neurosci 2010; 30: 12777-12786.

18 Turner G, Turner B, Collins E: X-linked mental retardation without physicalabnormality: Renpenning's syndrome. Dev Med Child Neurol 1971; 13: 71-78.

19 Suthers GK, Turner G, Mulley JC: A non-syndromal form of X-linked mentalretardation (XLMR) is linked to DXS14. Am J Med Genet 1988; 30: 485-491.

20 Gedeon A, Kerr B, Mulley J, Turner G: Pericentromeric genes for non-specific X-linked mental retardation (MRX). Am J Med Genet 1994; 51: 553-564. 